\title{
Overexpression of p54 rrb/NONO induces differential EPHA6 splicing and contributes to castration-resistant prostate cancer growth
}

\author{
Ryuji Yamamoto ${ }^{1}$, Tsuyoshi Osawa ${ }^{1}$, Yusuke Sasaki ${ }^{1}$, Shogo Yamamoto ${ }^{2}$, Motonobu \\ Anai ${ }^{1}$, Kouji Izumi ${ }^{3}$, Yoshihiro Matsumura4, Juro Sakai ${ }^{4,5}$, Hiroyuki Aburatani ${ }^{2}$, \\ Atsushi Mizokami ${ }^{3}$, Tatsuhiko Kodama ${ }^{1}$ and Toshiya Tanaka ${ }^{1}$ \\ ${ }^{1}$ Laboratory for Systems Biology and Medicine (LSBM), Research Center for Advanced Science and Technology (RCAST), The \\ University of Tokyo, Tokyo 153-8904, Japan \\ ${ }^{2}$ Division of Genome Science, Research Center for Advanced Science and Technology (RCAST), The University of Tokyo, \\ Tokyo 153-8904, Japan \\ ${ }^{3}$ Department of Integrative Cancer Therapy and Urology, Division of Cancer Medicine, Graduate School of Medical Science, \\ Kanazawa University, Kanazawa, Ishikawa 920-8641, Japan \\ ${ }^{4}$ Division of Metabolic Medicine, Research Center for Advanced Science and Technology (RCAST), The University of Tokyo, \\ Tokyo 153-8904, Japan \\ ${ }^{5}$ Division of Molecular Physiology and Metabolism, Tohoku University Graduate School of Medicine, Sendai 980-8574, Japan \\ Correspondence to: Toshiya Tanaka, email: tanaka@lsbm.org \\ Keywords: CRPC; neuroendocrine prostate cancer; p54 nrb/NONO; RNA splicing; EPHA6 \\ Abbreviations: PCa-prostate cancer, CRPC-castration-resistant prostate cancer, LNCaP-SF-LNCaP steroid free \\ Received: August 24, $2017 \quad$ Accepted: January 02, $2018 \quad$ Published: January 08, 2018 \\ Copyright: Yamamoto et al. This is an open-access article distributed under the terms of the Creative Commons Attribution License 3.0 \\ (CC BY 3.0), which permits unrestricted use, distribution, and reproduction in any medium, provided the original author and source \\ are credited.
}

\section{ABSTRACT}

The non-POU domain-containing octamer binding protein p54 $^{\text {nrb }} /$ NONO is a multifunctional nuclear protein involved in RNA splicing, processing, and transcriptional regulation of nuclear hormone receptors. Through chromosome copy number analysis via whole-exome sequencing, we revealed amplification of the chromosome Xq11.22-q21.33 locus containing the androgen receptor $(A R)$ and NONO genes in androgen-independent, castration-resistant prostate cancer (CRPC)like LNCaP-SF cells. Moreover, NONO was frequently amplified and overexpressed in patients with CRPC. RNA sequencing data revealed that a truncated ephrin type-A receptor 6 (EPHA6) splice variant (EPHA6-001) was overexpressed in LNCaP-SF cells, and knockdown of NONO or EPHA6-001 prevented EPHA6-001 expression and reduced proliferation and invasion by LNCaP-SF cells grown under androgen deprivation conditions. Growth inhibition and differential splicing of EPHA6 mRNA by p54 ${ }^{\text {rb }} /$ NONO were confirmed in gene silencing experiments in 22Rv1 PCa cells. Importantly, NONO knockdown in LNCaP-SF cells led to reduced tumor growth in castrated mice. These findings indicate that $\mathbf{p} 54^{\text {nrb }} /$ NONO is amplified and overexpressed in CRPC cells and clinical samples, and facilitates CRPC growth by mediating aberrant EPHA6 splicing. We therefore propose that $\mathrm{p} 54^{\mathrm{nrb}} / \mathrm{NONO}$ constitutes a novel and attractive therapeutic target for CRPC. 


\section{INTRODUCTION}

Prostate cancer $(\mathrm{PCa})$ is one of the most common cancers in men worldwide and a leading cause of cancer mortality $[1,2]$. During the early stages of $\mathrm{PCa}$, tumors are usually dependent on androgens for cellular function and growth; accordingly, androgen deprivation therapy (ADT) is the first-line treatment for patients with locally advanced tumors and recurrent or metastatic disease. However, the majority of patients will progress to castrationresistant PCa (CRPC) within 2-3 years after initiation of ADT [3]. Amplification and/or overexpression of the androgen receptor $(A R)$ gene is observed in approximately $30 \%$ of CRPCs [4, 5], and often sensitizes the AR to its antagonists, causing the latter to exhibit agonistic activity [6]. In addition, several AR mutations and truncated forms, which allow broad-range ligand binding to alternative steroids or mediate constitutive AR signaling, have also been associated with CRPC [5]. Therefore, although the androgen-AR signaling axis still plays a pivotal role in CRPC development, androgen-independent mechanisms also contribute to disease progression [7].

Alternative splicing and associated transcripts play important roles in cancer development, progression, and response to therapy [8-10]. For instance, splicing variants of the AR [5], transient receptor potential melastatin 8 (TRPM8) [11], prolactin receptor (PRLR) [12], epidermal growth factor receptor (EGFR) [13], and vascular endothelial growth factor (VEGF) [14] have been found to regulate cell growth, metastasis, and possibly the epithelial-mesenchymal transition (EMT) in PCa. Specifically, certain constitutively active AR splice variants (AR-Vs), particularly AR-V7, have been implicated in the development of castration resistance [5]. Overexpression of short-form splice variants of TRPM8 $\alpha$, which encode N-terminal fragments of fulllength TRPM8, has been shown to enhance migration and invasion in LNCaP cells [11]. Exon-4-deleted EGFR (de4 EGFR) was detected in $27 \%$ of PCa samples but not in normal tissue, and its overexpression reduced E-cadherin expression and increased metastatic potential in a glioma cell line [13]. Interestingly, these aberrant truncated variants result from alternative splicing at $3^{\prime}$ splice sites in the most common isoforms, and can confer tumor cells with a more mesenchymal phenotype, resulting in increased potential for migration and invasion. Therefore, cancer-specific splice variants and their regulatory splicing factors are attractive therapeutic targets.

The non-POU domain-containing octamer binding protein $\mathrm{p} 54^{\text {nrb }} / \mathrm{NONO}$ is a multifunctional nuclear protein involved in RNA splicing, processing, and transcriptional regulation of nuclear hormone receptors. The $\mathrm{p} 54^{\text {nrb/ }}$ NONO protein belongs to the Drosophila behavior human splicing (DBHS) protein family, which includes PTB-associated splicing factor (PSF) and paraspeckle protein component 1 (PSPC1); these proteins perform specific functions by forming homo- or heterodimers. p5 $4^{\text {nrb }} / \mathrm{NONO}$ possesses conserved N-terminal RNA recognition motifs (RRMs), a NonA/paraspeckle domain (NOPS), and a C-terminal coiled coil [15, 16], and also interacts with various proteins such as transcription factors, RNA polymerase II, splicing factors, exonuclease XRN2, DNA topoisomerase, and Ku70/Ku80 [15-23]. Although $\mathrm{p} 54^{\text {nrb }} / \mathrm{NONO}$ has been suggested to play a role in cancer development [24, 25], its differential expression and functional involvement in the development and progression of $\mathrm{PCa}$ have not been clarified.

We previously showed that human LNCaP-SF cells, which were generated from $\mathrm{LNCaP}$ cells under steroidfree conditions, acquire not only androgen-independent characteristics but also an osteoplastic phenotype [26]. In the current study, we aimed to identify the mechanisms underlying the acquisition of androgen-independent cell growth and invasive capacity by using whole-exome sequencing and transcriptome analyses of LNCaP-SF cells and available data from CRPC patients. Our findings provide important insights into the role of $\mathrm{p} 54^{\text {nrp }} / \mathrm{NONO}$ in RNA splicing and PCa progression to CRPC.

\section{RESULTS}

\section{Transcriptome analysis of differentially regulated genes affecting CRPC-like properties in LNCaP-SF cells}

LNCaP-SF cells derive from $\mathrm{LNCaP}$ cells and were isolated based on their ability to grow in the absence of androgen, thus representing an effective model of CRPC [26]. To clarify the mechanisms underlying the acquisition of androgen-independent cell growth, we first performed comprehensive gene expression profiling on parental (androgen-sensitive) LNCaP cells, and on LNCaP-SF cells transfected with scrambled siRNA (control) or AR-targeting siRNA (AR knockdown) using an oligonucleotide microarray. As reported [27], AR mRNA and protein levels were higher in LNCaP-SF cells compared with parental LNCaP cells (Figure 1A). AR knockdown effectively reduced AR mRNA and protein expression and blocked cell proliferation under androgendeprivation conditions (Figures 1A-1B), reflecting ligandbinding-domain mutations in the AR gene that confer the corresponding protein with constitutive activity. Compared with parental LNCaP cells, 236 and 274 probe sets were increased and decreased, respectively, in LNCaP-SF cells (Figure 1C and Supplementary Tables 1 and 2). In contrast, 34 probe sets were upregulated, and 33 probe sets were downregulated $>2$-fold following silencing of AR (Figure 1C and Supplementary Tables 3 and 4). Although the downregulated genes included several known AR targets such as KLK2, KLK3, ABHD2, ZBTB16, HMGCS1, and $A L D H 1 A 3$ [28], we found that only 10 probe sets (7 genes; Figure 1C and Supplementary Table 5) overlapped 
between upregulated probe sets in LNCaP-SF cells (LNCaP-SF/LNCaP) and downregulated probe sets after transfection with AR siRNA (siAR/siControl LNCaPSF cells). Similarly, with the exception of the known AR target gene $H P G D$, the top 20 upregulated genes in LNCaP-SF cells were not clearly downregulated by AR silencing (Figure 1D). These upregulated genes included some known to be associated with $\mathrm{PCa}$ invasion and bone metastasis, such as TNFRSF11B, EPHA3, EPHA6, and $B M P 2$ [29-32]. These data indicate the importance of ARindependent signaling in the acquisition of the CRPC-like phenotype in LNCaP-SF cells.

\section{$\mathrm{p5}^{\mathrm{nrb}} / \mathrm{NONO}$ is frequently amplified in CRPC}

To identify AR-independent signaling molecules associated with CRPC development, genomic differences between parental LNCaP and LNCaP-SF cells were analyzed by whole-exome sequencing. We identified 3,510 somatic mutations (Supplementary Table 6), which included 728 nonsynonymous mutations, 267 synonymous mutations, 110 protein-altering insertions and/ or deletions (indels), 4 non-frameshift deletions, 50 gains and/or losses, 1,427 intronic mutations, 129 mutations in the 3 '-untranslated region (UTR), 77 mutations in the 5'-UTR, and 718 mutations of other types. Changes in T877A and additional mutations of AR were not observed in LNCaP-SF cells. Chromosome copy number analysis identified 11 regions of copy gains and losses (Figure 2A and Supplementary Table 7) in LNCaP-SF compared with LNCaP cells. In particular, we observed a high level of amplification of the Xq11.22-q21.33 locus (Figure 2B), a region encoding 263 probe sets (Supplementary Table 8), in LNCaP-SF cells. Based on our stringent criteria, 31 of 47 expressed genes were found to be overexpressed in these cells (Figure 2C and Supplementary Table 9), including several ones associated with metastasis progression, such as $A R, M E D 12$, and $O G T$ [3-5, 33-35]. In searching for novel genes that might regulate differential gene expression in CRPC, we noted that NONO, a gene encoding a multifunctional RNA splicing and processing factor, was located within this amplified region. Indeed, we confirmed by gene-specific qPCR and immunoblotting that $\mathrm{p} 54^{\mathrm{nrb}}$ NONO mRNA and protein were increased in LNCaPSF cells compared with parental LNCaP cells (Figure 2D). Importantly, these in vitro findings were consistent with expression analyses that indicated frequent $N O N O$ amplification (Supplementary Figure 1) and significant induction of p54 nrb/NONO mRNA (Figure 2E) in clinical CRPC samples [36]. In addition, amplification of this region was observed in approximately $35 \%$ of neuroendocrine PCa specimens (Figure 2F) [37]. Since the neuroendocrine phenotype is closely associated with the development of metastatic CRPC, our findings suggest the importance of $p 54^{n r b} / N O N O$ amplification in the acquisition of CRPC-like properties.

\section{p54 $4^{\mathrm{nrb}} / \mathrm{NONO}$ regulates the expression of a truncated EPHA6 splice variant in LNCaP-SF cells}

To evaluate the effects of $\mathrm{p} 54^{\mathrm{nrb}} / \mathrm{NONO}$ on gene expression, we knocked down p54 $4^{\text {nrb }} / \mathrm{NONO}$ in LNCaPSF cells and performed RNA-seq. Treatment with two independent siRNAs resulted in greater than $70 \%$ knockdown of $\mathrm{p} 54^{\mathrm{nrb}} / \mathrm{NONO} \mathrm{mRNA}$ and protein in LNCaP-SF cells (Figure 3A). Compared with parental LNCaP cells, 488 and 422 transcripts were upregulated and downregulated, respectively, in LNCaP-SF cells (Figure 3B and Supplementary Tables 10 and 11). In contrast, 18 transcripts were found to be upregulated, and 5 transcripts were found to be downregulated greater than 2-fold after $\mathrm{p} 54^{\mathrm{nrb}} / \mathrm{NONO}$ silencing (Figure 3B and Supplementary Tables 12 and 13). We found 5 overlapping genes (NONO, EPHA6, CYP7A1, CRISP3, and RINL) when comparing changes between differentially expressed genes after p54 ${ }^{\text {nrb}} / \mathrm{NONO}$ silencing in LNCaP-SF cells and gene expression data from control LNCaP-SF and LNCaP cells (Figure 3B). RNA-seq analyses suggested that $\mathrm{p} 54^{\mathrm{nrb}} / \mathrm{NONO}$ had only a minor effect on the total number of altered transcripts in LNCaP-SF cells. Instead, we found that silencing of $\mathrm{p} 54^{\mathrm{nrb}} / \mathrm{NONO}$ induced aberrant RNA splicing of EPHA6, which encodes an ephrin receptor reported to be overexpressed and to promote angiogenesis and metastasis in human $\mathrm{PCa}$ [31] (Figure 3C). The full-length (FL) EPHA6 gene consists of 18 exons (encoding 1130 amino acids), while its C-terminally truncated EPHA6-001 variant (encoding 547 amino acids) is produced by addition of $36 \mathrm{bp}$ (12 amino acids) after exon 5 and a 3'-UTR of 371 bp (Figure 3D). Importantly, RNA-seq results showed that EPHA6001 was significantly upregulated in LNCaP-SF cells compared with LNCaP cells, and p54 nrb/NONO knockdown specifically reduced RNA fragment reads corresponding to exons 4 and 5. To confirm this finding, qPCR was performed using primer sets designed to span an exon-exon junction of EPHA6 mRNA. As expected, we observed a significant decrease in the expression of transcripts spanning exons 4 to 5 in p $54^{\text {nrb}} /$ NONOsilenced LNCaP-SF cells (Figure 3E). These results suggest that $\mathrm{p} 54^{\mathrm{nrb}} / \mathrm{NONO}$ induces aberrant RNA splicing of EPHA6 to generate the truncated EPHA6-001 variant, and that reduced EPHA6-001 expression upon $\mathrm{p} 54^{\mathrm{nrb}} / \mathrm{NONO}$ silencing is not due to suppressed EPHA6 transcription.

Next, we evaluated the effect of siRNA-mediated silencing of EPHA6-001 (siEPHA6-2) on the androgenindependent growth of LNCaP-SF cells. Although knockdown efficiency was approximately 35\%, EPHA6001 silencing in LNCaP-SF cells significantly reduced androgen-independent cell growth by $38 \%$ (Figures $3 \mathrm{~F}$ 3G). 
A

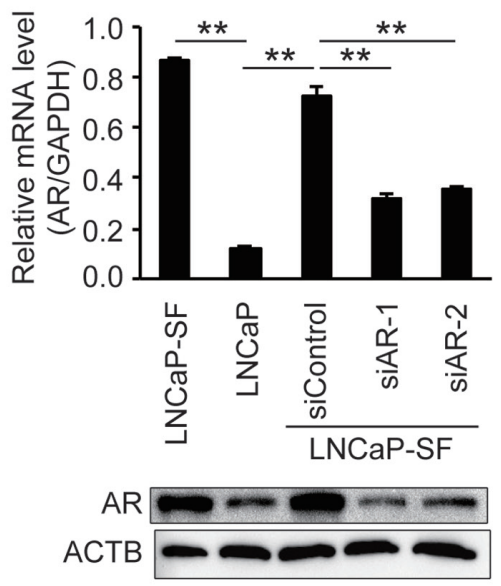

C

\section{LNCaP-SF/LNCaP $\geq 2$}

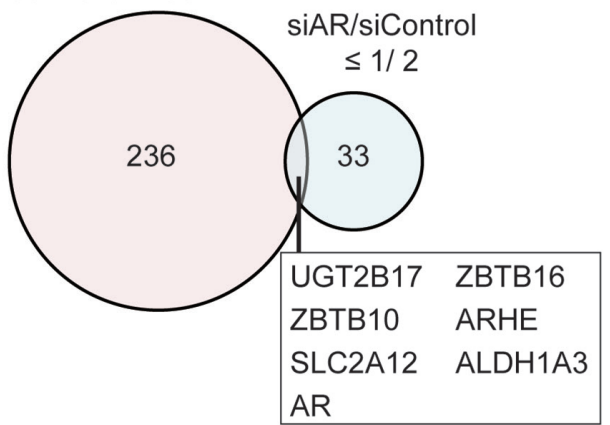

B
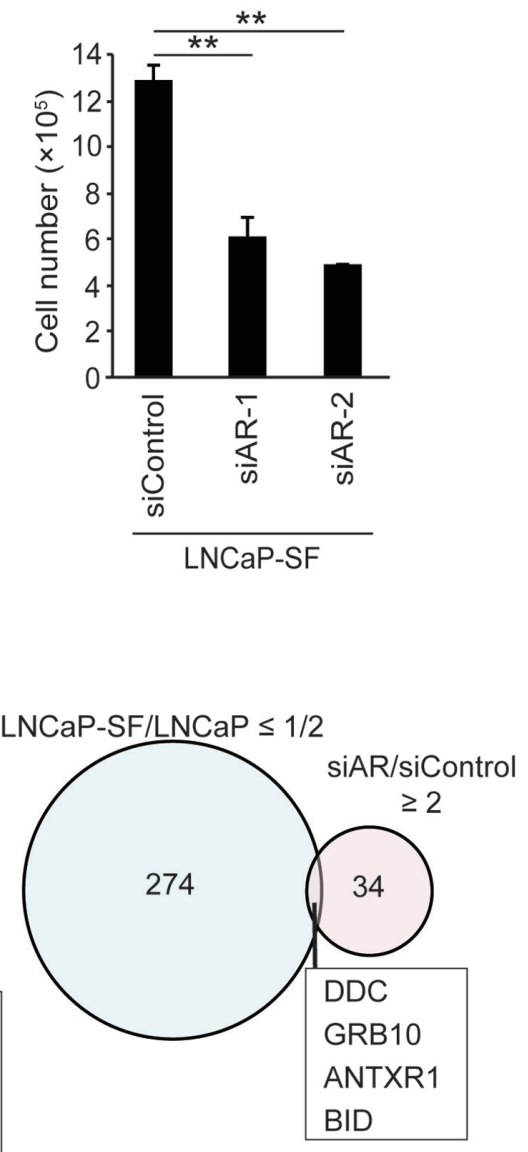

D

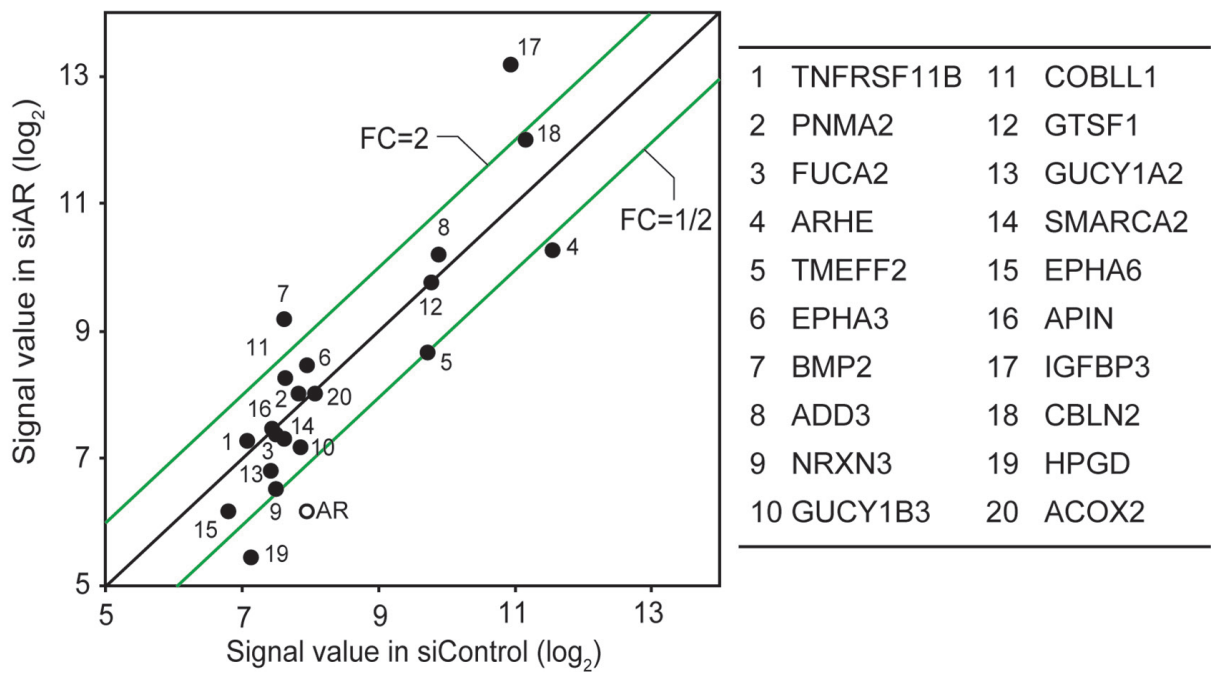

Figure 1: Effect of $A R$ silencing on gene expression and growth in LNCaP-SF cells. (A) Representative qPCR and immunoblot showing that siRNA-mediated AR knockdown effectively reduced AR mRNA and protein expression in LNCaP-SF cells. (B) The growth rate of LNCaP-SF cells under androgen deprivation conditions was significantly reduced by siAR transfection. (C) Venn diagram showing the overlap of genes differentially expressed in LNCaP-SF/LNCaP cells compared with siAR-regulated transcripts in LNCaP-SF cells. Probe sets labeled light magenta were upregulated, while those labeled light cyan were downregulated. (D) Scatter plot analysis of gene expression differences between siRNA control and siAR. The top 20 differentially expressed genes in LNCaP-SF/LNCaP are listed in the right panel; the AR signal value is plotted between the siRNA control and siAR-treated LNCaP-SF cells. FC: fold change. Data represent mean \pm s.e.m. ${ }^{* *} \mathrm{P}<0.01$. 


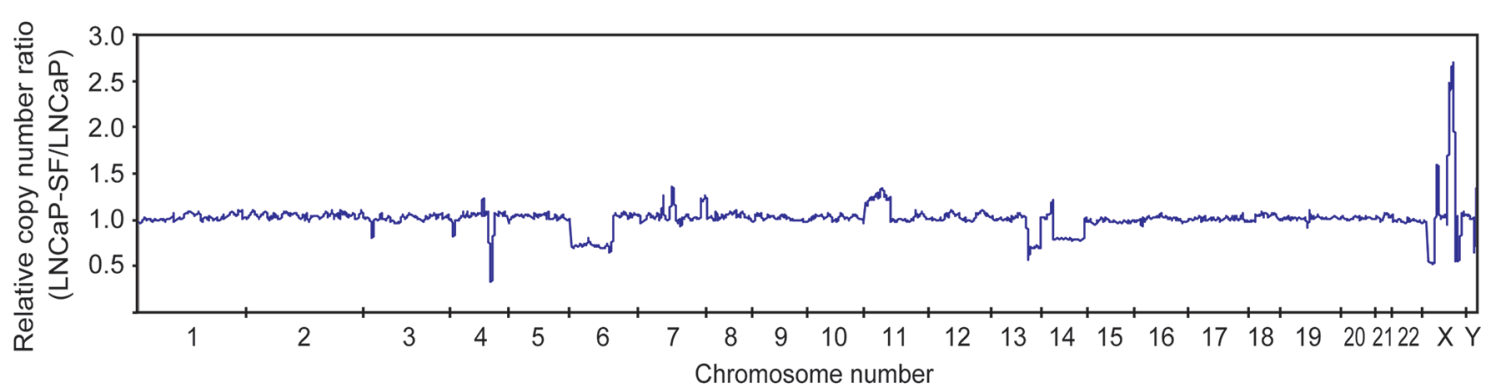

B

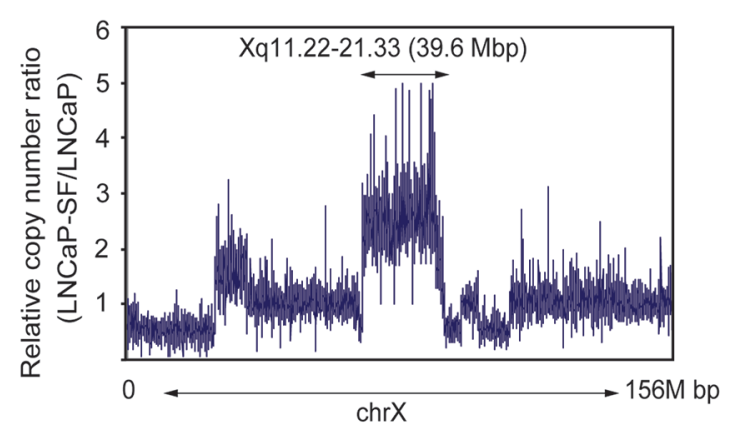

D

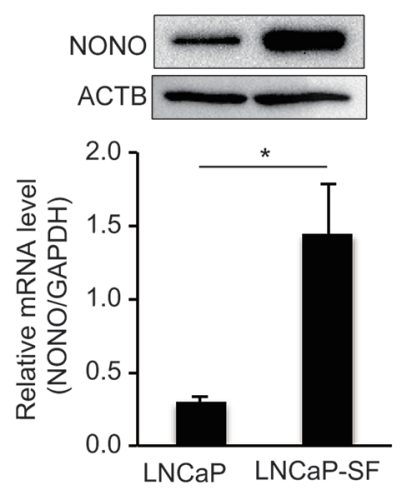

E
C

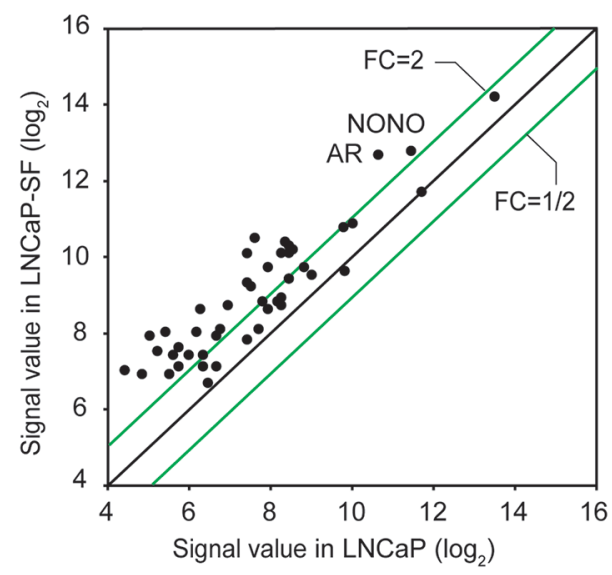

(Grasso CS et al. Nature 2012) NONO

(A_24_P413437)

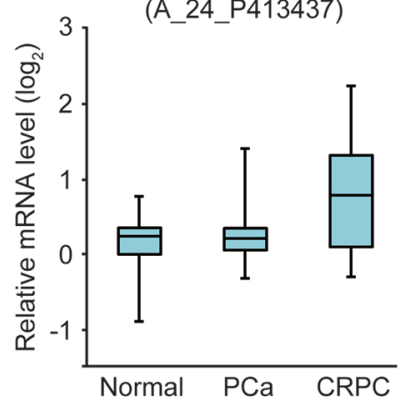

AR

(A_23_P113111)

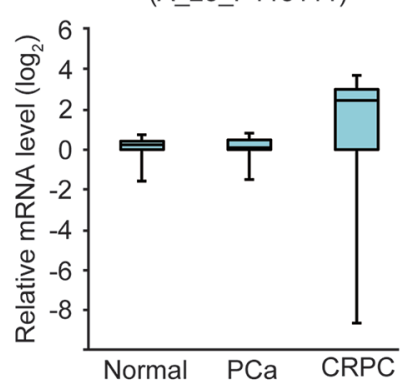

F (Beltran $\mathrm{H}$ et al. Nature Medicine 2016)

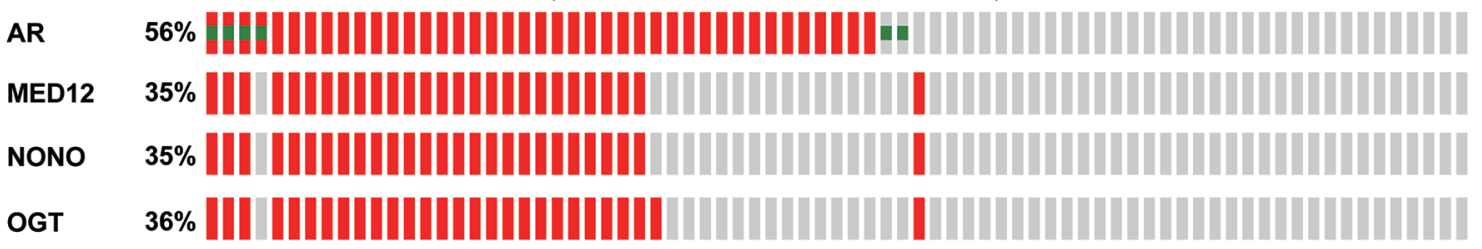

Genetic Alteration

Amplification $\mathbf{n}$ Missense Mutation (putative driver)

Figure 2: Amplification of the NONO gene in LNCaP-SF cells and CRPC samples. (A) Relative DNA copy number profile of LNCaP-SF cells. (B) Relative DNA copy number of chromosome X. Amplification of chromosome Xq11.22-q21.33 was observed in LNCaP-SF cells. (C) Scatter plot analysis of genes on chromosome Xq11.22-q21.33 showing expression differences between LNCaP-SF and parental LNCaP cells. (D) LNCaP-SF cells show increased p54 ntrb/NONO mRNA and protein expression. (E) Relative p54 $54^{\text {nrb }} / \mathrm{NONO}$ and AR mRNA expression in PCa, CRPC, and normal tissue samples from the Grasso et al. data set (39). p5 $4^{\text {ntb }} / \mathrm{NONO}$ mRNA expression was upregulated in CRPC. (F) Frequency of amplification (red bar) and mutation (green bar) for AR, MED12, OGT, and NONO in the Beltran et al. data set (cBioportal; http://www.cbioportal.org) (40). The percentages shown reflect the overall rate of gene amplification and mutation. Vertical aligned bars indicate samples from the same patient. Data represent mean \pm s.e.m. 
A

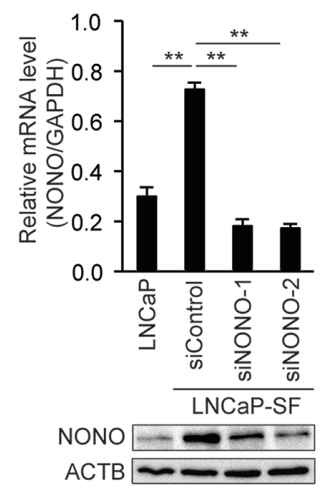

B

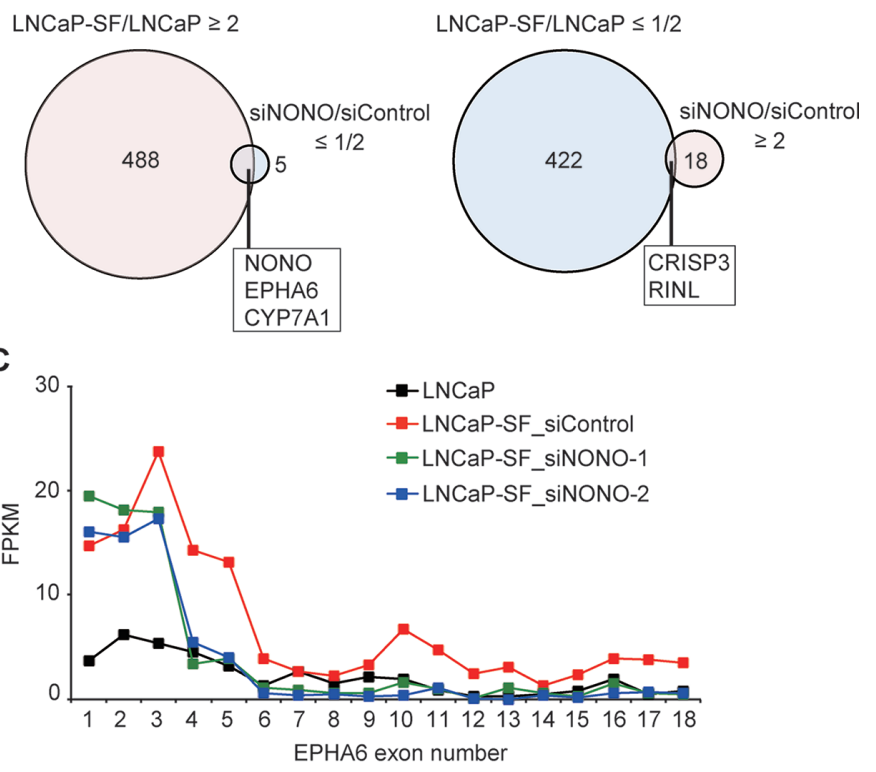

D

EPHA6 gene (Cytogenetic location: 3q11.2)

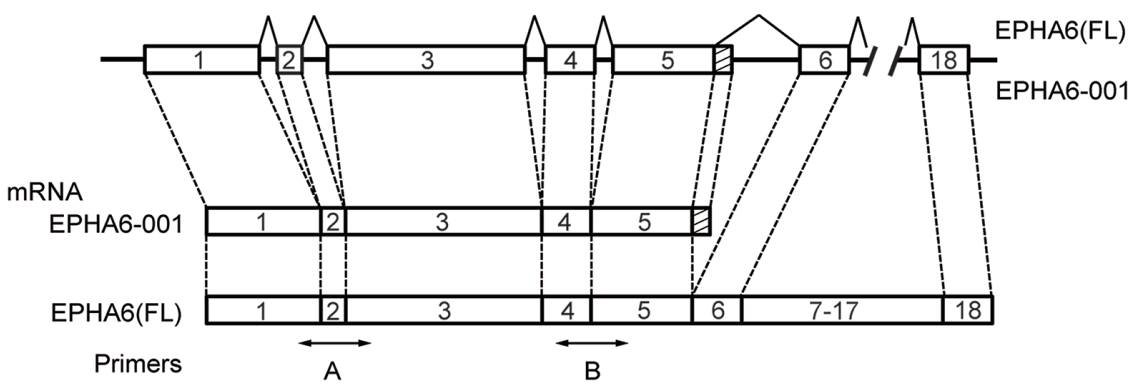

E

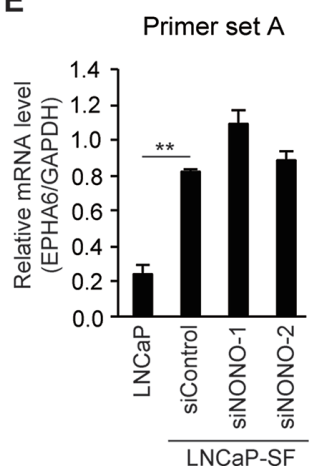

F

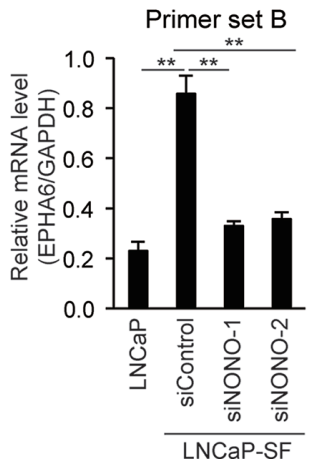

G

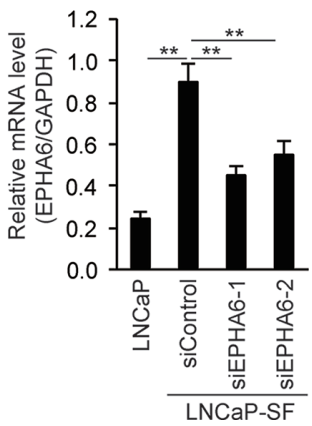

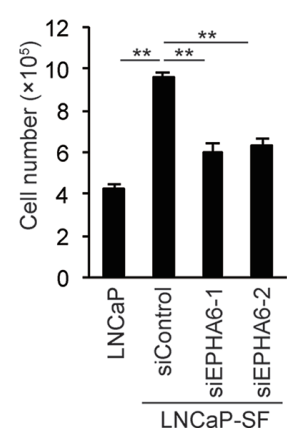

Figure 3: 554 $^{\text {nrb}} /$ NONO mediates differential splicing of the $\boldsymbol{E P H A 6}$ gene. (A) Representative qPCR and immunoblot showing that siNONOs effectively reduced $\mathrm{p} 54^{\text {nrb }} / \mathrm{NONO}$ mRNA and protein expression in LNCaP-SF cells. (B) Venn diagram showing the overlap of transcripts differentially expressed in LNCaP-SF/LNCaP cells and siNONO-regulated transcripts. Transcripts labeled light magenta were upregulated, and those labeled light cyan were downregulated. (C) Fragments per kilobase of exon per million mapped fragments (FPKM) values of EPHA6 exons. Exons 1-5 were significantly increased in LNCaP-SF cells. p54 ${ }^{\text {nrb}} / \mathrm{NONO}$ silencing specifically reduced the FPKM value corresponding to exons 4 and 5. (D) Schematic gene structure comparison between full length EPHA6 (FL) and its truncated splice variant EPHA6-001. Transcription of EPHA6-001 is initiated from the same first exon of the EPHA6 (FL) gene and the unique C-terminal sequence of 12 amino acids is encoded by an extended exon downstream of exon 5. Specific primer pairs across exons 1 to 3 (primer set A) and exons 4 and 5 (primer set B) are indicated. (E) Effect of siNONOs on EPHA6-001 expression in LNCaP-SF cells. siNONOs markedly reduced exons 4-5 of mRNA EPHA6 expression in LNCaP-SF cells (data obtained using the primer set B). (F) Effect of EPHA6 common (siEPHA6-1) and EPHA6-001 specific (siEPHA6-2) siRNAs on EPHA6-001 expression in LNCaP-SF cells. (G) Transfection with siEPHA6s significantly reduced the growth rate of LNCaP-SF cells under androgen deprivation conditions. Data represent mean \pm s.e.m. ${ }^{* *} \mathrm{P}<0.01$. 


\section{Knockdown of $\mathrm{p5}^{\text {nrb/NONO inhibits growth and }}$ invasion in LNCaP-SF cells}

Because tumor growth under androgen deprivation conditions is a hallmark of CRPC, we next assessed the effects of $\mathrm{p} 54^{\text {nrb }} / \mathrm{NONO}$ on the growth of LNCaP-SF cells under androgen deprivation conditions. We used two independent shRNAs to stably knockdown p54 nrb/NONO in LNCaP-SF cells. Consistent with the results of siRNA experiments (Figure 3), p54 ${ }^{\text {nrb }} / \mathrm{NONO}$ shRNAs effectively suppressed $\mathrm{p} 54^{\mathrm{nrb}} / \mathrm{NONO} \mathrm{mRNA}$ and protein expression and downregulated the $\mathrm{p} 54^{\mathrm{nrb}} / \mathrm{NONO}$ target EPHA6001, compared with LNCaP-SF cells transfected with untargeted control shRNA (Figures 4A-4B). Compared with parental LNCaP cells, under androgen deprivation conditions LNCaP-SF cells exhibited an accelerated growth rate, which was decreased by $\mathrm{p} 54^{\text {nrb }} / \mathrm{NONO}$ knockdown (Figure 4C). This result was further supported by the observation that LNCaP-SF cell growth was also suppressed by siRNA-mediated knockdown of $\mathrm{p} 54^{\mathrm{nrb}} /$ NONO (Supplementary Figure 2).

Next, to examine the role of $\mathrm{p} 54^{\mathrm{nrb}} / \mathrm{NONO}$ in the metastatic process, we performed in vitro invasion assays by counting the cells that migrated through a Matrigel basement membrane. The number of LNCaP-SF invading cells, which was significantly larger than that of parental LNCaP cells, was reduced after transfection with two independent p54 nrb $/$ NONO shRNAs (Figure 4D).

To further verify the effect of $\mathrm{p} 54^{\mathrm{nrb}} / \mathrm{NONO}$ on EPHA6 mRNA splicing and cell growth in CRPC cells, we performed siRNA-mediated p5 $4^{\text {nrb}} / \mathrm{NONO}$ knockdown in another androgen-insensitive $\mathrm{PCa}$ cell line, i.e. 22Rv1 cells (Figure 5A). Similar to LNCaP-SF cells, p54 nrb/NONO knockdown in 22Rv1 cells induced aberrant EPHA6 mRNA splicing (Figure 5B) and reduced cell growth rate (Figure $5 \mathrm{C}$ ), whereas $A R-V 7$ expression was not changed (Figure 5D). To assess whether similar effects could be observed in non-CRPC cells, p54 ${ }^{\text {nrb} / ~}$ NONO knockdown was performed in human umbilical vein endothelial cells (HUVECs). Although a significant downregulation of $\mathrm{p} 54^{\mathrm{nrb}} / \mathrm{NONO}$ mRNA (Figure $5 \mathrm{E}$ ) and protein expression was achieved, no statistically significant reduction was noted in HUVECs' growth rate (Figure 5F). On the other hand, EPHA6 mRNA was essentially undetectable in HUVECs ( $\mathrm{Ct}$ values above $35)$. Altogether, these data suggest that the $\mathrm{p} 54^{\mathrm{nrb}} / \mathrm{NONO}-$ EPHA6 axis may be a specific regulator of proliferation and invasion in CRPC cells.

\section{p54 nrb/NONO knockdown suppresses xenograft tumor growth}

We then evaluated the effects of $\mathrm{p} 54^{\mathrm{nrb}} / \mathrm{NONO}$ knockdown on tumor growth in castrated male mice, in which the residual androgen level is insufficient to maintain the growth of androgen-dependent PCa cells.
Castrated male SCID mice were injected subcutaneously with LNCaP-SF cells transfected with shControl, shNONO-1, or shNONO-2 shRNAs and examined every 3 or 4 days for evidence of tumor engraftment and tumor volume measurements. Parental LNCaP cells did not form tumors until 6 weeks after injection, and these tumors grew slowly (Figure 6A). In contrast, LNCaP-SF shControl cells exhibited greater than $90 \%$ engraftment efficiency during the experimental period and a rapid growth rate (Figures 6A-6B). Also, tumors formed from LNCaP-SF shControl cells were larger and produced higher levels of serum PSA (Figure 6D) than those derived from parental LNCaP cells. In contrast, p54 ${ }^{\mathrm{nrb}} /$ NONO knockdown in LNCaP-SF cells suppressed tumor formation and reduced growth rate and serum PSA levels (Figures 6A-6D). Taken together, these data suggest that amplification of $\mathrm{p} 54^{\mathrm{nrb}} / \mathrm{NONO}$ has an important role in the progression of PCa to CRPC.

\section{DISCUSSION}

Since aberrant AR reactivation is commonly involved in the progression of $\mathrm{PCa}$ to CRPC, understanding the AR signaling-independent and cooperative mechanisms underlying the transition to CRPC is essential to develop successful therapies. Although many groups have generated and tested androgen-independent $\mathrm{PCa}$ cell lines, their findings often lacked clinically relevant, confirmatory data. In the current study, several notable findings were made using the androgen-independent LNCaP-SF cell line established by us [26]. First, amplification of the Xq11.22-q21.33 chromosomal region, which encodes the $A R$ gene, was detected in LNCaP-SF cells and verified in CRPC and neuroendocrine PCa clinical samples. Second, Xq11.22-q21.33 amplification correlated with overexpression of $\mathrm{p} 54^{\mathrm{nrb}} / \mathrm{NONO}$, which in turn induced overexpression of the truncated EPHA6 gene variant EPHA6-001. Third, p54 ${ }^{\mathrm{nrb}} / \mathrm{NONO}$ and EPHA6 silencing experiments indicated that the $\mathrm{p} 54^{\mathrm{nrb}} / \mathrm{NONO}-$ EPHA6-001 axis stimulates the growth of LNCaP-SF cells under androgen deprivation conditions.

$\mathrm{X}$-chromosome genes are known to be frequently associated with specific cancers [38]. A seminal study by Visakorpi et al. reported that $30 \%$ of ADT patients with recurrent $\mathrm{PCa}$ tumors showed amplification of the Xq11-q13 chromosomal region containing the AR gene [4]. Later, evidence showed that the Xq11.22-q21.33 locus includes not only $A R$, but also $M E D 12, O G T$, and NONO [3-5, 33-35]. Although numerous reports indicated that AR amplification drives CRPC $[4,5]$, other genes located in this region have also been implicated in PCa development and progression. Somatic mutations and overexpression of MED12 have been reported in CRPC [33, 34]. MED12 is a subunit of the Mediator complex, an evolutionarily conserved transcriptional regulator that regulates Wnt, 
sonic hedgehog $(\mathrm{SHH})$, and transforming growth factor- $\beta$ (TGF $\beta$ ) signaling pathways [33, 39, 40]. Similarly, the OGT enzyme, which mediates O-glcNAcylation of multiple proteins, has been shown to be overexpressed in PCa and to play a role in PCa invasion, angiogenesis, and metastasis [35]. Indeed, amplification of $A R, M E D 12$, $O G T$, and NONO has been observed in both metastatic and neuroendocrine PCa [36, 37]. Thus, our results suggest that the acquisition of a CRPC-like phenotype in LNCaP-SF cells via Xq11.22-q21.33 amplification resembles the pathogenic events leading to CRPC, and indicate that LNCaP-SF cells are a suitable research tool for studying the mechanisms of CRPC progression and for drug screening.

p5 $4^{\text {nrb }} / \mathrm{NONO}$ is a multifunctional nuclear protein involved in many aspects of gene expression and RNA splicing and processing $[15,16]$. We found, however, that a small number of genes were differentially regulated by $\mathrm{p} 54^{\mathrm{nrb}} / \mathrm{NONO}$ silencing in LNCaP-SF cells. Homoand heterodimers of the Drosophila behavior/human splicing (DBHS) protein family members SFPQ, PSPC1, and $\mathrm{p} 54^{\mathrm{nrb}} / \mathrm{NONO}$ have been shown to interact with transcription factors, DNA, and RNA, to exert various functions. SFPQ/NONO has been reported to bind to
A

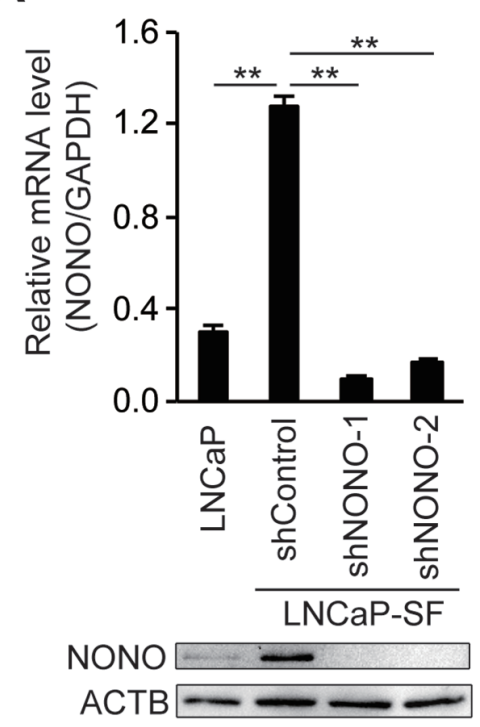

D

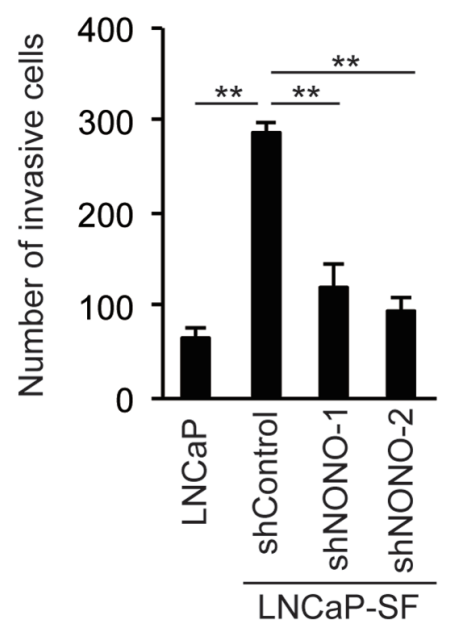

B

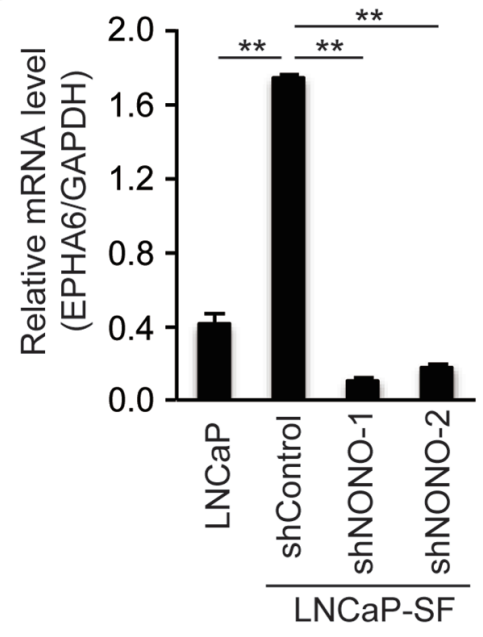

C

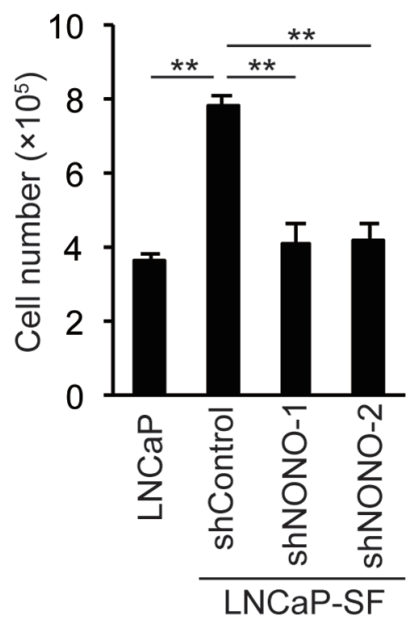

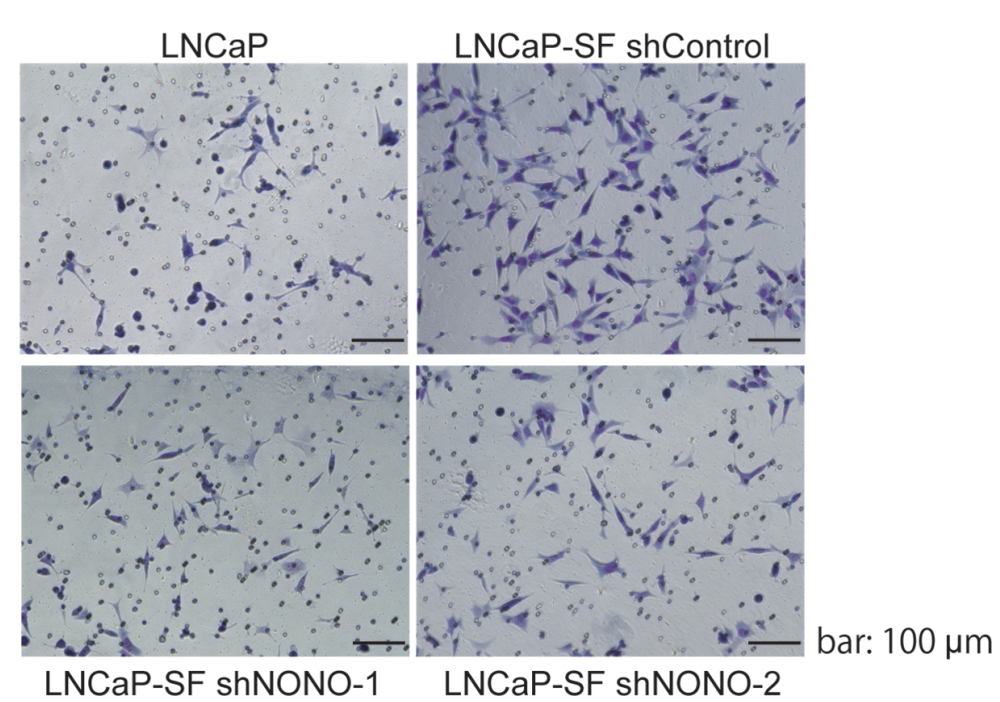

Figure 4: NONO silencing reduces LNCaP-SF cell growth and invasion. qPCR and immunoblot showing that levels of p54 ${ }^{\text {nrb/ }}$ NONO (A) and EPHA6 (B) transcripts were efficiently reduced in LNCaP-SF cells after transduction with a lentivirus carrying two different shNONOs. (C) Transduction with shNONOs effectively reduced the growth rate of LNCaP-SF cells under androgen deprivation conditions. (D) Transduction with shNONOs significantly reduced the invasion ability of LNCaP-SF cells. A representative result of the cell invasion assay among the four groups of cells is shown. Data represent mean \pm s.e.m. ${ }^{* *} \mathrm{P}<0.01$. 
nuclear receptors such as thyroid hormone receptor [17], progesterone receptor [41], and steroidogenic factor 1 (SF-1) to negatively regulate their transcription [18]. Also, Yadav et al. reported that NONO is associated with the promoters of many transcriptionally active genes and activates rhodopsin and a subset of phototransduction genes [42]. In addition, SFPQ/NONO is required for efficient transcriptional termination, pre-mRNA 3 '-end processing, paraspeckle formation, and DNA repair $[15,16]$. Li et al. reported that NONO knockout can be rescued by upregulation of the PSPC1 paralog and formation of a functional heterodimer with SFPQ during DNA repair [43]. In accordance with this observation, we found that PSPC1 expression was significantly induced by $\mathrm{p} 54^{\text {nrb}} / \mathrm{NONO}$ silencing in LNCaP-SF cells. Therefore, PSPC1 might compensate for the loss of $\mathrm{p} 54^{\mathrm{nrb}} / \mathrm{NONO}-$ regulated gene expression and function. However, our results suggested that other DHBS family proteins may not compensate for specific functions of $\mathrm{p} 54^{\mathrm{nrb}} / \mathrm{NONO}$ in LNCaP-SF cells including, critically, production of the EPHA6-001 transcript by alternative RNA splicing. This fact correlates well with evidence that knockdown of p5 $44^{\text {nrb}} / \mathrm{NONO}$ in the retina specifically induces splicing defects and altered expression of the rhodopsin gene [42], and the observation that spontaneous upregulation of PSPC1 and SFPQ could not rescue the behavioral deficits caused by NONO ablation in mice nor the intellectual disabilities caused by NONO mutations in humans [44].

Alternative splicing is a crucial gene regulation mechanism that increases functional proteomic diversity and controls multiple aspects of development. Its dysregulation is implicated in various human diseases including cancer [8-10], where specific splicing isoforms contribute to tumor progression and the acquisition of a metastatic phenotype [11-14]. Along these lines, the present work revealed that a truncated splice variant of the EPHA6 gene (EPHA6-001), is overexpressed in androgen-independent LNCaP-SF cells and contributes critically to proliferation under androgen deprivation conditions. Eph receptors and their ligands, ephrins, regulate important cell communication systems and have widespread roles in both normal physiology and disease, affecting also the growth, migration, and invasion of
A

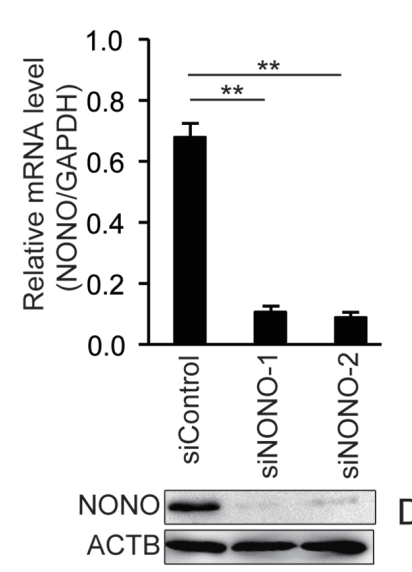

B

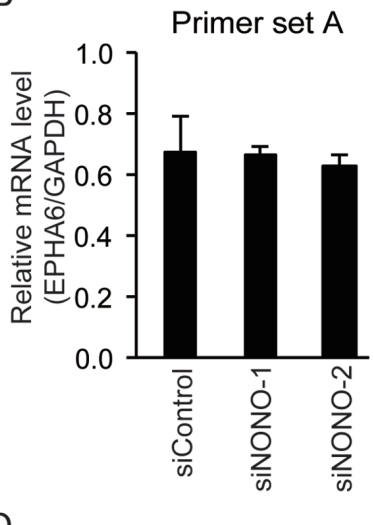

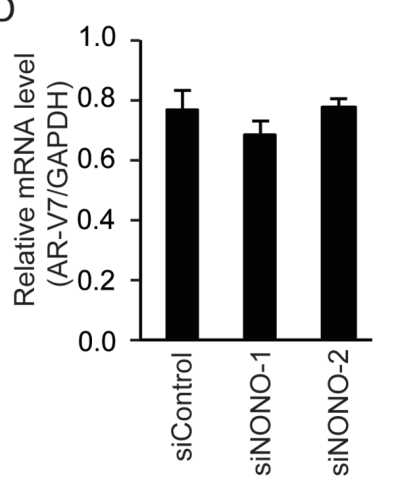

Primer set B
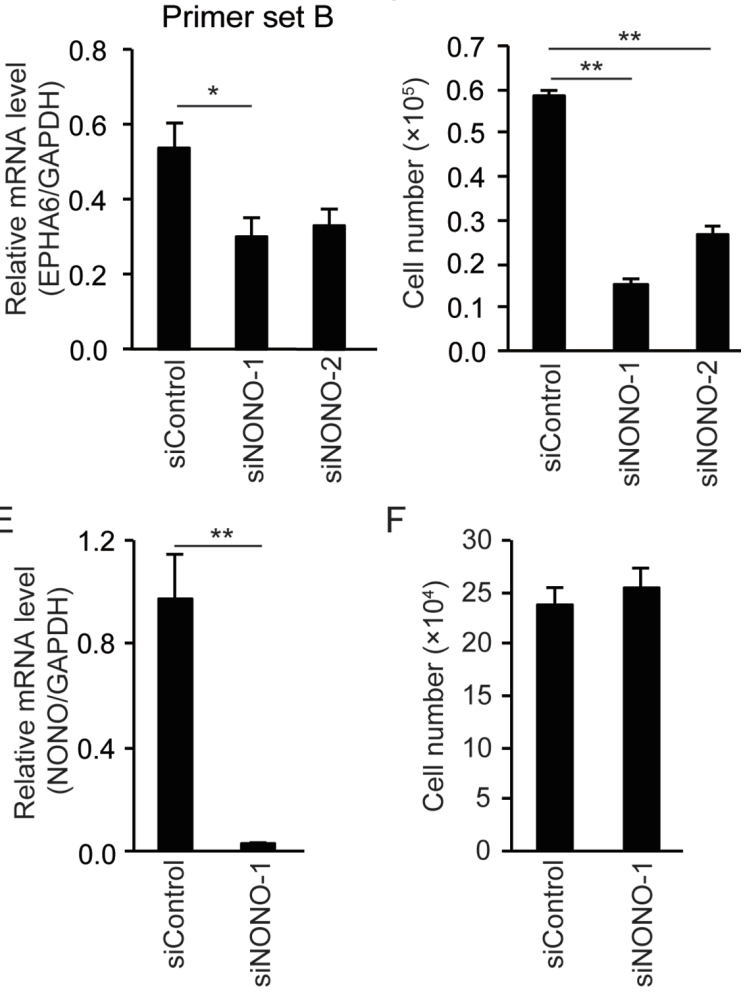

F

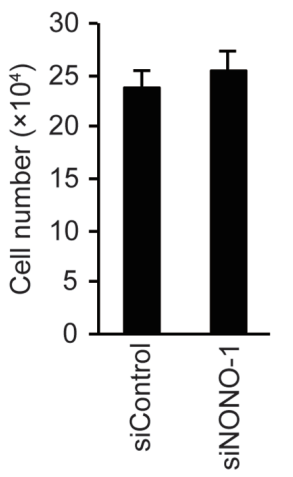

Figure 5: NONO knockdown inhibits growth of 22Rv1 cells but not of HUVECs. (A) Representative qPCR and immunoblot showing that siNONOs effectively reduced $\mathrm{p} 54^{\text {nrb }} / \mathrm{NONO}$ mRNA and protein expression in 22Rv1 cells. (B) Transfection with siNONOs markedly reduced transcripts spanning exons 4 to 5 of EPHA6 in 22Rv1 cells (data obtained using EPHA6 primer set B). (C) Transfection with siNONOs significantly reduced the growth rate of 22Rv1 cells. (D) $A R-V 7$ expression was not affected by siNONOs in $22 \mathrm{Rv} 1$ cells. (E) Reduced NONO mRNA expression in siNONO-1-transfected HUVECs. (F) No significant reduction of cell growth rate was observed in siNONO-1-transfected HUVECs. Data represent mean \pm s.e.m. ${ }^{* *} \mathrm{P}<0.01$. 
cancer cells [45]. Recently, Li et al. reported that EPHA6 is consistently overexpressed in metastatic PCa. In their report, shRNA targeting a common region of both fulllength and truncated splice variants of EPHA6 seemed to decrease tumor angiogenesis and metastasis to a larger degree, compared with an shRNA that targeted only full length EPHA6 [31]. This is consistent with our present data, and suggests that alternative splicing of the EPHA6 gene plays a critical role in tumor growth and metastasis in CRPC. Similar to NONO, EPHA6 ablation or mutation is associated with behavioral deficits in mice and intellectual disability in humans [46, 47]. Therefore, although the precise mechanisms underlying $\mathrm{p} 54^{\mathrm{nrb}} / \mathrm{NONO}$-mediated regulation of EPHA6 splicing are not fully understood, these observations indicate that the $\mathrm{p} 54^{\mathrm{nrb}} / \mathrm{NONO}-\mathrm{EPHA} 6$ axis has pivotal roles in both neurodevelopment and CRPC progression.

In summary, the current study and previous observations indicate that $\mathrm{p} 54^{\mathrm{nrb}} / \mathrm{NONO}$ is overexpressed in both AR-independent PCa cells and CRPC samples, and by differentially regulating EPHA6 splicing and expression it facilitates CRPC growth. Because other DBHS family members may compensate for most of $\mathrm{p} 54^{\mathrm{nrb}} / \mathrm{NONO}$ cellular functions after its loss, but don't appear to affect EPHA6 splicing nor expression, p54 ${ }^{\text {nrb/ }}$ NONO may be an ideal therapeutic target for CRPC.
A

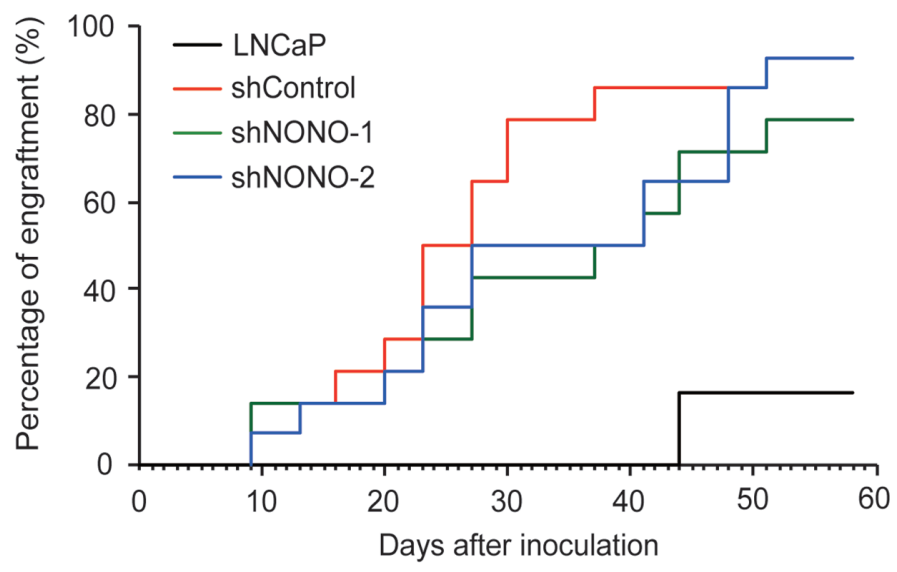

B

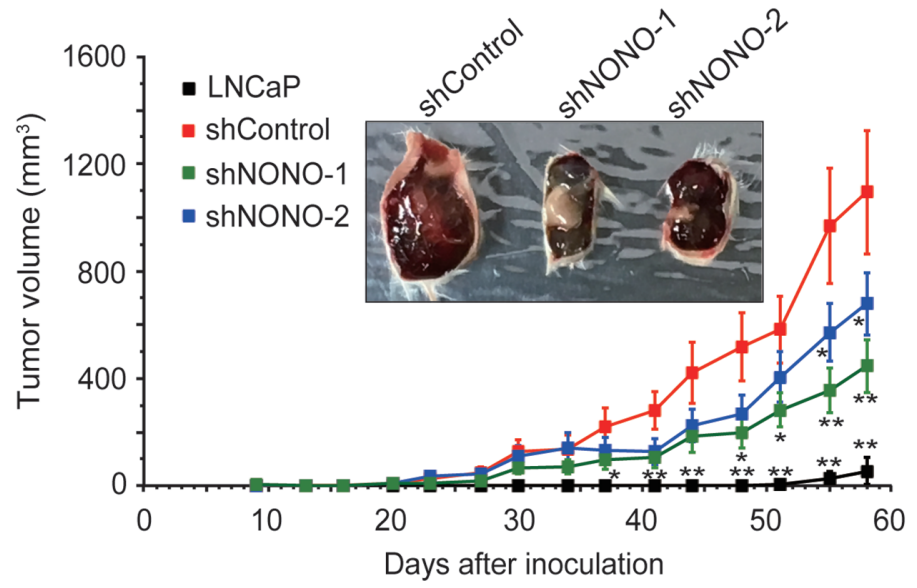

C

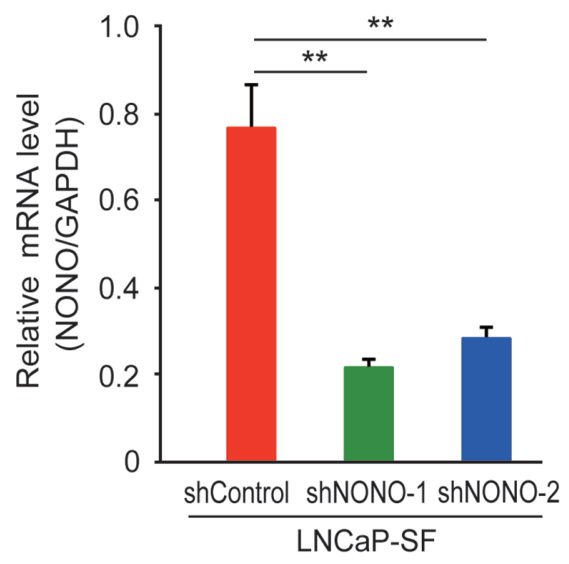

D

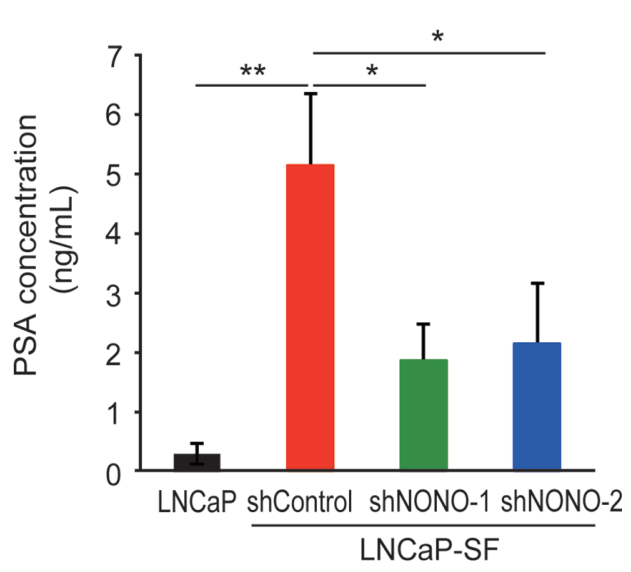

Figure 6: Effect of NONO silencing on LNCaP-SF tumor xenograft growth. (A) Effect of p54 $4^{\text {nrb }} / \mathrm{NONO}$ shRNAs on engraftment ability of LNCaP-SF cells. Tumor engraftment was scored as positive when tumors were visually detected. (B) Effect of p54 ${ }^{\text {nrb }} / \mathrm{NONO}$ shRNAs on LNCaP-SF tumor growth. (C) p54 nrb/NONO shRNAs effectively downregulated NONO transcription in LNCaP-SF tumors. (D) Serum PSA levels were significantly reduced by shNONOs. Data represent mean \pm s.e.m. ${ }^{*} \mathrm{P}<0.05 ;{ }^{* *} \mathrm{P}<0.01$. 


\section{MATERIALS AND METHODS}

\section{Cell culture}

The human prostate cancer $\mathrm{LNCaP}$ cell line was purchased from the American Type Culture Collection (ATCC) and maintained in Dulbecco's-modified Eagle's medium (DMEM) (Sigma-Aldrich) supplemented with $10 \%$ heat-inactivated fetal bovine serum (FBS) containing antibiotics (penicillin, $50 \mathrm{IU} / \mathrm{mL}$; streptomycin, $50 \mu \mathrm{g} / \mathrm{mL}$ ) at $37^{\circ} \mathrm{C}$ in $5 \% \mathrm{CO}_{2}$. LNCaP-SF cells were established after long-term subculture of parental LNCaP cells in DMEM and 5\% charcoal-stripped fetal calf serum (CCS) [26] and maintained in DMEM supplemented with 5\% CCS and antibiotics at $37^{\circ} \mathrm{C}$ in $5 \% \mathrm{CO}_{2}$. The human prostate cancer 22Rv1 cell line was purchased from ATCC and maintained in Roswell Park Memorial Institute 1640 medium (RPMI 1640; Gibco) supplemented with 10\% heat-inactivated FBS containing antibiotics (penicillin, 50 $\mathrm{IU} / \mathrm{mL}$; streptomycin, $50 \mu \mathrm{g} / \mathrm{mL}$ ) at $37^{\circ} \mathrm{C}$ and $5 \% \mathrm{CO}_{2}$. Human umbilical vein endothelial cells (HUVECs) were purchased from KURABO (Cat\#: KE-4109P10, Strain No. 04609, Osaka, Japan) and maintained in EGM-2 bullet kit medium (CC-3162, Lonza, Walkersville, MD).

\section{Small interfering RNA (siRNA) transfection}

Silencer ${ }^{\circledR}$ Select siRNAs (Thermo Fisher Scientific) targeting AR, NONO, EPHA6, and EPHA6-001 were used to inhibit the expression of the corresponding transcripts. The day before transfection, $1 \times 10^{5}$ cells/ well were plated in 6-well plates. Cells (LNCaP-SF, 22Rv1, or HUVECs) were transfected with siRNA using Lipofectamine RNAiMAX transfection reagent (Thermo Fisher Scientific) in Opti-MEM (Thermo Fisher Scientific) according to the manufacturer's protocol. All the siRNA sequences used in this study are listed in Supplementary Table 14

\section{Short hairpin RNA (shRNA) transduction}

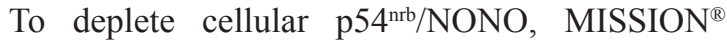
Lentiviral Packaging Mix and lentiviral shRNA transfer vectors (Sigma-Aldrich) were cotransfected into 293FT cells using Lipofectamine 2000 (Life Technologies). Briefly, $30 \mu \mathrm{l}$ of Lentiviral Packaging mix (SigmaAldrich), $3 \mu \mathrm{g}$ of pLKO.1-puro Non-Mammalian shRNA Control, NONO-1 (TRCN0000286628), or NONO-2 (TRCN0000286693), and $1.5 \mathrm{ml}$ of Opti-MEM were mixed. This was combined with a pre-incubated (5 min) mix of Lipofectamine $2000(36 \mu \mathrm{l})$ and Opti-MEM solution $(1.5 \mathrm{ml})$, and incubated for $20 \mathrm{~min}$ at room temperature. The DNA-Lipofectamine 2000 complex was added to a $10 \mathrm{~cm}^{2}$ plate containing $5 \mathrm{ml}$ of Opti-MEM containing $10 \%$ FBS. Five $\mathrm{ml}$ of a $1.2 \times 10^{6}$ cells $/ \mathrm{ml}$ 293FT cell suspension in Opti-MEM containing 10\% FBS were added to the plate. Viral supernatants were harvested
$72 \mathrm{~h}$ after transfection. LNCaP-SF cells were infected with the lentivirus stock with $6 \mu \mathrm{g} / \mathrm{ml}$ of polybrene. Twentyfour hours after transduction, media was replaced with fresh complete media containing $4 \mu \mathrm{g} / \mathrm{ml}$ puromycin to select stable cell clones. All the shRNA sequences used in this study are listed in Supplementary Table 15.

\section{Exome capture, library construction, and sequencing}

Total DNA was extracted from LNCaP-SF cells and parental LNCaP cells using the PureLink ${ }^{\mathrm{TM}}$ Genomic DNA Mini Kit (Life Technologies). One microgram of DNA per sample was sheared with a Covaris SS Ultrasonicator. We used a Sciclone NGS workstation (Caliper Life Sciences) for automated library construction. Exome capture was performed with Agilent SureSelect Human All Exon Kit v4 (Agilent Technologies). Each sample was sequenced on an Illumina HiSeq 2000 system using a read length of $2 \times$ $100 \mathrm{bp}$. Image analysis and base calling were performed using the Illumina pipeline with default settings [48]. Summary statistics and data quality metrics for whole exome sequencing are shown in Supplementary Table 16.

\section{Exome sequence processing}

Exome reads were mapped to the human genome (GRCh37/hg19) using Burrows-Wheeler Aligner (BWA) and Novoalign software independently. Reads with a minimal editing distance to the reference genome were taken to represent optimal alignments. Then, bam files were locally realigned with SRMA. Normal-tumor pair bam files were processed using an in-house genotyper (karkinos; https://sourceforge.net/projects/karkinos/).

\section{Transcriptome microarray analysis}

For genome-wide transcription analysis, the GeneChip Human Genome U133 Plus 2.0 array was used as previously described $[49,50]$. Briefly, total RNA was extracted with ISOGEN (Nippon Gene) from LNCaP, LNCaP-SF, and LNCaP-SF cells treated with siRNAs (non-targeting control, siAR-1, and siAR-2). Following in vitro transcription (IVT) and cRNA fragmentation, the fragmented IVT product was hybridized on an array and stained with streptavidin phycoerythrin according to the manufacturer's recommended protocol. The arrays were scanned using the Affymetrix GeneChip Scanner 3000 (Affymetrix), and GeneChip Analysis Suite software program version 5.0 (Affymetrix) was used to calculate the signal value for each gene probe.

\section{Quantitative microarray analysis}

Gene expression levels and fold changes between samples were calculated using the GeneChip Analysis Suite software program version $5.0[49,50]$. The signal 
value in each experiment was normalized to 100 . The criteria for significant induction of a particular gene were a signal value $\geq 100$ for the objective samples and a fold change $\geq 2^{1}$. The criteria for significant expression reduction for a particular gene was a signal value $\geq 100$ for the control samples and a fold change $\leq 2^{-1}$.

\section{RNA-sequencing}

RNA quality was assessed by Nanodrop measurement (Thermo Fisher Scientific). RNAsequencing (RNA-Seq) libraries were prepared using TruSeq Rapid PE Cluster Kit and TruSeq Rapid SBS kit (Illumina). The libraries were sequenced on Illumina HiSeq 2500 using a read length of $2 \times 150 \mathrm{bp}$. RNA-seq reads were demultiplexed using CASAVA v1.8.2 and aligned to human transcriptome (UCSC gene) and genome (GRCh37/hg19) references respectively using BWA [51]. After transcripts' coordinates were converted to genomic positions, an optimal mapping result was selected either from transcript or genome mapping by comparing the minimal edit distance to the reference. Local realignment was performed within in-house short reads aligner with smaller $\mathrm{k}$-mer size $(\mathrm{k}=11)$. Finally, fragments per kilobase of exon per million mapped fragments (fpkm) values were calculated for each UCSC gene while considering strandspecific information. Summary sequencing statistics and data quality metrics are shown in Supplementary Table 17.

\section{Quantitative real-time PCR (qPCR)}

First-strand cDNA was synthesized from total RNA with oligo dT primers using the SuperScript ${ }^{\mathbb{B}}$ III FirstStrand Synthesis System (Thermo Fisher Scientific). qPCR was performed using SYBR green PCR Master Mix (Perkin-Elmer Life Sciences) in 384-well plates using the CFX384 Real-Time system (Bio-Rad) [49]. All reactions were performed in triplicate. The relative amount of all mRNAs was calculated using the comparative CT method. GAPDH mRNA was used as the invariant control for all studies. Primers used for qPCR are listed in Supplementary Table 18.

\section{Immunoblotting}

Cells on 6-well plates were lysed with $300 \mu$ of RIPA buffer (Thermo Scientific) supplemented with complete protease inhibitor cocktail (Roche). Protein concentration was determined by the Bradford method (Bio-Rad). Whole-cell samples were resolved by SDSpolyacrylamide gel electrophoresis using 10\% Ready Gel (Bio-Rad), then electro-transferred to Immobilon transfer membranes (Millipore). Membranes were blocked with 5\% skim milk (Wako Pure Chemical Industries, Ltd.) in TBS with $0.1 \%$ Tween-20 for $30 \mathrm{~min}$ at room temperature. The blot was probed with primary antibodies overnight at $4^{\circ} \mathrm{C}$ and then incubated with anti-IgG horseradish peroxidase-conjugated antibodies (SigmaAldrich) for $1 \mathrm{~h}$ at room temperature. Proteins were detected using SuperSignal CL-HRP Substrate System (Thermo Fisher Scientific) according to the instructions of the manufacturer. Immunoreactive protein bands were documented using a Bio-Rad ChemiDoc XRS+ system (Bio-Rad). Antibodies used for immunoblot are listed in Supplementary Table 19.

\section{Cell growth assay}

Cells were seeded in 6-well plates at a concentration of $1 \times 10^{5}$ cells per well. Twenty-four hours later, cells were treated with various siRNAs, and cultured for an additional 2 (HUVECs) or 6 days. Media and reagents were replaced at day 3 . At the end of the culture period, the cells were trypsinized and counted with a hemocytometer.

\section{Cell invasion assay}

Cell invasion ability was evaluated using 24well BD BioCoat Matrigel Invasion Chambers (BD Bioscience) as per the manufacturer guidelines. $2 \times 10^{5}$ cells were added to the upper wells onto an $8 \mu \mathrm{m}$ pore size PET membrane coated with a thin layer of matrigel basement membrane matrix. After $16 \mathrm{~h}$ of incubation, cells were stained with Diff Quick stain (Sysmex) after removing the non-migrated cells from the top of the membrane with Q-tips. After air-drying, the cells that had migrated to the underside of the filter were counted using a light microscope (Leica) in four randomly selected fields (magnification: 40×). Each assay was performed in triplicate.

\section{Mouse xenograft studies}

Five-week-old male SCID mice were obtained from Charles River Laboratories (Japan) and maintained in a laminar air flow cabinet under specific pathogenfree conditions. After one week of adaptation, castration was performed under anesthesia by making a small incision in the scrotum to remove each testicle after ligation of the cord. Mice were allowed to recover for an additional 1 week before inoculation with $\mathrm{PCa}$ tumor cells: LNCaP ( $\mathrm{n}=7$ mice), LNCaP-SF shControl ( $\mathrm{n}=14$ mice), LNCaP-SF shNONO-1 $(\mathrm{n}=14$ mice) or shNONO-2 $(\mathrm{n}=14$ mice) to generate a xenograft model of human prostate cancer. To this end, a total of $100 \mu \mathrm{L}$ of cell suspension containing $5.0 \times 10^{6}$ cells and 50\% of matrigel was injected subcutaneously into the dorsal flanks of the mice via a 29-gauge needle. Body weight and tumor size were measured every 3 or 4 days. Calipermeasured tumor volume was calculated by the formula: larger diameter $\times(\text { smaller diameter })^{2} \times 0.5$ [26]. The mice used in the current study were maintained and sacrificed in accordance with the guidelines of the Committee on Animal Experimentation of the University of Tokyo. 


\section{PSA enzyme immunoassay}

Mouse serum was frozen at $-80^{\circ} \mathrm{C}$ until PSA measurement, performed using a human PSA Enzyme Immunoassay kit (Markit M PA, Dainippon Pharmaceutical).

\section{Statistical analyses}

Homogeneity in variance was evaluated by Bartlett's test followed by parametric or non-parametric Dunnett's multiple comparison test. Significance was assessed at ${ }^{*} P$ $<0.05,{ }^{* *} P<0.01$.

\section{CONFLICTS OF INTEREST}

The authors declare no conflicts of interest associated with this manuscript.

\section{FUNDING}

This work was supported by the Project for Cancer Research And Therapeutic Evolution (P-CREATE) from the Japan Agency for Medical Research and Development (AMED).

\section{REFERENCES}

1. National Cancer Institute (2012). SEER Stat Fact Sheets: Prostate Cancer National Cancer Institute. http://seer.cancer. gov/statfacts/html/prost.html.

2. American Cancer Society (2015). Cancer Facts and Figures 2015. http://www.cancer.org/acs/groups/content/@editorial/ documents/document/acspc-044552.pdf.

3. Harris WP, Mostaghel EA, Nelson PS, Montgomery B. Androgen deprivation therapy: progress in understanding mechanisms of resistance and optimizing androgen depletion. Nat Clin Pract Urol. 2009; 6:76-85.

4. Visakorpi T, Hyytinen E, Koivisto P, Tanner M, Keinänen R, Palmberg C, Palotie A, Tammela T, Isola J, Kallioniemi OP. In vivo amplification of the androgen receptor gene and progression of human prostate cancer. Nat Genet. 1995; 9:401-406.

5. Watson PA, Arora VK, Sawyers CL. Emerging mechanisms of resistance to androgen receptor inhibitors in prostate cancer. Nat Rev Cancer. 2015; 15:701-711.

6. Chen CD, Welsbie DS, Tran C, Baek SH, Chen R, Vessella R, Rosenfeld MG, Sawyers CL. Molecular determinants of resistance to antiandrogen therapy. Nat Med. 2004; 10:33-39.

7. Mizokami A, Namiki M. Reconsideration of progression to CRPC during androgen deprivation therapy. J Steroid Biochem Mol Biol. 2015; 145:164-171.

8. Biamonti G, Bonomi S, Gallo S, Ghigna C. Making alternative splicing decisions during epithelial-tomesenchymal transition (EMT). Cell Mol Life Sci. 2012; 69:2515-2526.
9. David CJ, Manley JL. Alternative pre-mRNA splicing regulation in cancer: pathways and programs unhinged. Genes Dev. 2010; 24:2343-2364.

10. Hagen RM, Ladomery MR. Role of splice variants in the metastatic progression of prostate cancer. Biochem Soc Trans. 2012; 40:870-4.

11. Peng M, Wang Z, Yang Z, Tao L, Liu Q, Yi LU, Wang X. Overexpression of short TRPM8 variant $\alpha$ promotes cell migration and invasion, and decreases starvation-induced apoptosis in prostate cancer LNCaP cells. Oncol Lett. 2015; 10:1378-1384

12. Wu W, Ginsburg E, Vonderhaar BK, Walker AM. S179D prolactin increases vitamin $\mathrm{D}$ receptor and p21 through up-regulation of short $1 \mathrm{~b}$ prolactin receptor in human prostate cancer cells. Cancer Res. 2005; 65:7509-7515.

13. Wang H, Shi B, Zhang Q, Jiang H, Hu S, Kong J, Yao M, Yang S, Li Z. Growth and metastasis suppression of glioma xenografts expressing exon 4-deletion variant of epidermal growth factor receptor by monoclonal antibody $\mathrm{CH} 12$ mediated receptor degradation. FASEB J. 2012; 26:73-80.

14. Woolard J, Wang WY, Bevan HS, Qiu Y, Morbidelli L, Pritchard-Jones RO, Cui TG, Sugiono M, Waine E, Perrin R, Foster R, Digby-Bell J, Shields JD, et al. VEGF165b, an inhibitory vascular endothelial growth factor splice variant: mechanism of action, in vivo effect on angiogenesis and endogenous protein expression. Cancer Res. 2004; 64:7822-7835.

15. Knott GJ, Bond CS, Fox AH. The DBHS proteins SFPQ, NONO and PSPC1: a multipurpose molecular scaffold. Nucleic Acids Res. 2016; 44:3989-4004.

16. Lee AR, Hung W, Xie N, Liu L, He L, Dong X. Tyrosine residues regulate multiple nuclear functions of P54nrb. J Cell Physiol. 2016 In press.

17. Mathur M, Tucker PW, Samuels HH. PSF is a novel corepressor that mediates its effect through $\operatorname{Sin} 3 \mathrm{~A}$ and the DNA binding domain of nuclear hormone receptors. Mol Cell Biol. 2001; 21:2298-2311.

18. Sewer MB, Nguyen VQ, Huang CJ, Tucker PW, Kagawa N, Waterman MR. Transcriptional activation of human CYP17 in H295R adrenocortical cells depends on complex formation among $\mathrm{p} 54(\mathrm{nrb}) / \mathrm{NonO}$, protein-associated splicing factor, and SF-1, a complex that also participates in repression of transcription. Endocrinology. 2002; 143:1280-1290.

19. Chaoui A, Kavo A, Baral V, Watanabe Y, Lecerf L, Colley A, Mendoza-Londono R, Pingault V, Bondurand N. Subnuclear re-localization of SOX10 and p54NRB correlates with a unique neurological phenotype associated with SOX10 missense mutations. Hum Mol Genet. 2015; 24:4933-4947.

20. Izumi H, McCloskey A, Shinmyozu K, Ohno M. p54nrb/ NonO and PSF promote U snRNA nuclear export by accelerating its export complex assembly. Nucleic Acids Res. 2014; 42:3998-4007.

21. Kaneko S, Rozenblatt-Rosen O, Meyerson M, Manley JL. The multifunctional protein $\mathrm{p} 54 \mathrm{nrb} / \mathrm{PSF}$ recruits the 
exonuclease XRN2 to facilitate pre-mRNA 3' processing and transcription termination. Genes Dev. 2007; 21:1779-1789.

22. Kawano S, Miyaji M, Ichiyasu S, Tsutsui KM, Tsutsui K. Regulation of DNA Topoisomerase Ilbeta through RNA-dependent association with heterogeneous nuclear ribonucleoprotein U (hnRNP U). J Biol Chem. 2010; 285:26451-26460.

23. Ha K, Takeda Y, Dynan WS. Sequences in PSF/SFPQ mediate radioresistance and recruitment of PSF/SFPQcontaining complexes to DNA damage sites in human cells. DNA Repair (Amst). 2011; 10:252-259.

24. Pavao M, Huang YH, Hafer LJ, Moreland RB, Traish AM.

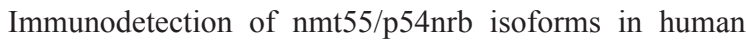
breast cancer. BMC Cancer. 2001; 1:15.

25. Schiffner S, Zimara N, Schmid R, Bosserhoff AK. p54nrb is a new regulator of progression of malignant melanoma. Carcinogenesis. 2011; 32:1176-1182.

26. Iwasa Y, Mizokami A, Miwa S, Koshida K, Namiki M. Establishment and characterization of androgenindependent human prostate cancer cell lines, LN-REC4 and LNCaP-SF, from LNCaP. Int J Urol. 2007; 14:233-239.

27. Ono A, Oka S, Okudaira H, Nkanishi T, Mizokami A, Kobayashi M, Schuster DM, Goodman MM, Shirakami Y, Kawai K. $\left[{ }^{14} \mathrm{C}\right]$ Fluciclovine(alias anti- $\left[{ }^{14} \mathrm{C}\right] \mathrm{FACBC}$ ) uptake and ASCT2 expression in castration-resistant prostate cancer cells. Nucl Med Biol. 2015; 42:887-892.

28. Jin HJ, Kim J, Yu J. Androgen receptor genomic regulation. Transl Androl Urol. 2013; 2:157-177.

29. Corey E, Brown LG, Kiefer JA, Quinn JE, Pitts TE, Blair JM, Vessella RL. Osteoprotegerin in prostate cancer bone metastasis. Cancer Res. 2005; 65:1710-1718.

30. Wu R, Wang H, Wang J, Wang P, Huang F, Xie B, Zhao Y, Li S, Zhou J. EphA3, induced by PC-1/PrLZ, contributes to the malignant progression of prostate cancer. Oncol Rep. 2014; 32:2657-2665.

31. Li S, Ma Y, Xie C, Wu Z, Kang Z, Fang Z, Su B, Guan M. EphA6 promotes angiogenesis and prostate cancer metastasis and is associated with human prostate cancer progression. Oncotarget. 2015; 6:22587-22597. https://doi. org/10.18632/oncotarget.4088

32. Graham TR, Agrawal KC, Abdel-Mageed AB. Independent and cooperative roles of tumor necrosis factor-alpha, nuclear factor-kappaB, and bone morphogenetic protein-2 in regulation of metastasis and osteomimicry of prostate cancer cells and differentiation and mineralization of MC3T3-E1 osteoblast-like cells. Cancer Sci. 2010; 101:103-111.

33. Shaikhibrahim Z, Offermann A, Braun M, Menon R, Syring I, Nowak M, Halbach R, Vogel W, Ruiz C, Zellweger T, Rentsch CA, Svensson M, Andren O, et al. MED12 overexpression is a frequent event in castrationresistant prostate cancer. Endocr Relat Cancer. 2014; 21:663-675.
34. Barbieri CE, Baca SC, Lawrence MS, Demichelis F, Blattner M, Theurillat JP, White TA, Stojanov P, Van Allen E, Stransky N, Nickerson E, Chae SS, Boysen G, et al. Exome sequencing identifies recurrent SPOP, FOXA1 and MED12 mutations in prostate cancer. Nat Genet. 2012; 44:685-9.

35. Lynch TP, Ferrer CM, Jackson SR, Shahriari KS, Vosseller K, Reginato MJ. Critical role of O-Linked $\beta$-N-acetylglucosamine transferase in prostate cancer invasion, angiogenesis, and metastasis. J Biol Chem. 2012; 287:11070-11081.

36. Grasso CS, Wu YM, Robinson DR, Cao X, Dhanasekaran SM, Khan AP, Quist MJ, Jing X, Lonigro RJ, Brenner JC, Asangani IA, Ateeq B, Chun SY, et al. The mutational landscape of lethal castration-resistant prostate cancer. Nature. 2012; 487:239-243.

37. Beltran H, Prandi D, Mosquera JM, Benelli M, Puca L, Cyrta J, Marotz C, Giannopoulou E, Chakravarthi BV, Varambally S, Tomlins SA, Nanus DM, Tagawa $\mathrm{ST}$, et al. Divergent clonal evolution of castrationresistant neuroendocrine prostate cancer. Nat Med. 2016; 22:298-305.

38. Spatz A, Borg C, Feunteun J. X-chromosome genetics and human cancer. Nat Rev Cancer. 2004; 4:617-629.

39. Rocha PP, Scholze M, Bleiss W, Schrewe H. Med12 is essential for early mouse development and for canonical Wnt and Wnt/PCP signaling. Development. 2010; 137:2723-2731.

40. Zhou H, Spaeth JM, Kim NH, Xu X, Friez MJ, Schwartz CE, Boyer TG. MED12 mutations link intellectual disability syndromes with dysregulated GLI3-dependent Sonic Hedgehog signaling. Proc Natl Acad Sci USA. 2012; 109:19763-19768.

41. Dong X, Yu C, Shynlova O, Challis JR, Rennie PS, Lye SJ. $\mathrm{p} 54 \mathrm{nrb}$ is a transcriptional corepressor of the progesterone receptor that modulates transcription of the labor-associated gene, connexin 43 (Gja1). Mol Endocrinol. 2009; 23:1147-1160.

42. Yadav SP, Hao H, Yang HJ, Kautzmann MA, Brooks M, Nellissery J, Klocke B, Seifert M, Swaroop A. The transcription-splicing protein $\mathrm{NonO} / \mathrm{p} 54 \mathrm{nrb}$ and three NonO-interacting proteins bind to distal enhancer region and augment rhodopsin expression. Hum Mol Genet. 2014; 23:2132-2144.

43. Li S, Li Z, Shu FJ, Xiong H, Phillips AC, Dynan WS. Double-strand break repair deficiency in NONO knockout murine embryonic fibroblasts and compensation by spontaneous upregulation of the PSPC1 paralog. Nucleic Acids Res. 2014; 42:9771-9780.

44. Mircsof D, Langouët M, Rio M, Moutton S, SiquierPernet K, Bole-Feysot C, Cagnard N, Nitschke P, Gaspar L, Žnidarič M, Alibeu O, Fritz AK, Wolfer DP, et al. Mutations in NONO lead to syndromic intellectual disability and inhibitory synaptic defects. Nat Neurosci. 2015; 18:1731-1736. 
45. Pasquale EB. Eph receptors and ephrins in cancer: bidirectional signalling and beyond. Nat Rev Cancer. 2010; 10:165-180.

46. Savelieva KV, Rajan I, Baker KB, Vogel P, Jarman W, Allen M, Lanthorn TH. Learning and memory impairment in Eph receptor A6 knockout mice. Neurosci Lett. 2008; 438:205-209.

47. Schneider A, Puechberty J, Ng BL, Coubes C, Gatinois V, Tournaire M, Girard M, Dumont B, Bouret P, Magnetto J, Baghdadli A, Pellestor F, Geneviève D. Identification of disrupted AUTS2 and EPHA6 genes by array painting in a patient carrying a de novo balanced translocation $\mathrm{t}(3 ; 7)$ with intellectual disability and neurodevelopment disorder. Am J Med Genet A. 2015; 167A: 3031-3037.

48. Kakiuchi M, Nishizawa T, Ueda H, Gotoh K, Tanaka A, Hayashi A, Yamamoto S, Tatsuno K, Katoh H, Watanabe Y, Ichimura T, Ushiku T, Funahashi S, et al. Recurrent gain-of-function mutations of RHOA in diffuse-type gastric carcinoma. Nat Genet. 2014; 46:583-7.

49. Tanaka T, Tahara-Hanaoka S, Nabekura T, Ikeda K, Jiang S, Tsutsumi S, Inagaki T, Magoori K, Higurashi T, Takahashi $\mathrm{H}$, Tachibana K, Tsurutani Y, Raza S, et al. PPAR $\beta / \delta$ activation of CD300a controls intestinal immunity. Sci Rep. 2014; 4:5412.

50. Raza-Iqbal S, Tanaka T, Anai M, Inagaki T, Matsumura Y, Ikeda K, Taguchi A, Gonzalez FJ, Sakai J, Kodama T. Transcriptome analysis of K-877 (a novel selective PPAR $\alpha$ modulator (SPPARM $\alpha$ ))-regulated genes in primary human hepatocytes and the mouse liver. J Atheroscler Thromb. 2015; 22:754-772.

51. Kushida N, Nomura S, Mimura I, Fujita T, Yamamoto S, Nangaku M, Aburatani H. Hypoxia-Inducible Factor-1 $\alpha$ Activates the Transforming Growth Factor- $\beta$ /SMAD3 Pathway in Kidney Tubular Epithelial Cells. Am J Nephrol. 2016; 44:276-285. 